\title{
Age-related eyelid changes
}

\author{
Jacqueline Mupas-Uy, MD, Yoshiyuki Kitaguchi, MD, PhD, Yasuhiro Takahashi, MD, PhD, Hirohiko Kakizaki, \\ $\mathrm{MD}, \mathrm{PhD}$
}

Department of Oculoplastic, Orbital \& Lacrimal Surgery, Aichi Medical University Hospital, Aichi, Japan

\begin{abstract}
Aging is a natural process where changes occur in multiple tissues, resulting in aesthetic and functional effects. Aging eyelids lead to a tired or sleepy appearance. Progressive changes continue throughout life; these may eventually affect the ocular surface and cause visual impairment. Objective is to report the pathophysiology of the common age-related eyelid disorders and the current management concepts. This article presents the pathophysiology and the surgical procedures of eyelid disorders, such as blepharoptosis, dermatochalasis, entropion, ectropion, baggy eyelids, epicanthus, and lateral canthal aging. In general, most agerelated eyelid changes are corrected due to its to its associated cosmetic and functional problems. Management is based on anatomic factors contributing to the eyelid disorder. Conclusion is the choice of surgical procedure is based on the exact localisation of the eyelid pathology.
\end{abstract}

Keywords: aging; eyelid; pathophysiology; disorder

\section{Introduction}

Aging of the eyelid is an inevitable process that is mostly noticeable in middle-aged and older adults. In some individuals, it is more apparent, which becomes aesthetically and functionally disturbing.

Degenerative changes occur in every part of the eyelid. Skin deterioration, soft tissue atrophy, laxity, and descent occur. Common eyelid disorders encountered are blepharoptosis, dermatochalasis, entropion, ectropion, and baggy eyelids.

Surgical procedures have been developed to restore eyelid appearance and function. A thorough understanding of the age-related anatomic abnormalities responsible for the occurrence of the abovementioned disorders is a pre-requisite before performing surgical procedures.

In this review article, we describe the pathophysiology of the common age-related eyelid disorders and report the current concepts to effectively correct the underlying eyelid pathology.

\section{Topographic change}

Aging causes skin, bony, and soft tissue changes, along with soft tissue descent. The skin loses luster and becomes more pigmented, coarse, and wrinkled. Loss of elastin and collagen in the skin, with preservation of the orbicularis muscle, leads to skin folds, rhytids, indistinct eyelid crease, and less epicanthal folds [1].

In the upper eyelid, the nasal fat pad oftentimes herniates and becomes prominent (Fig. 1) [2]. The central fat pad, namely the preaponeurotic fat pad, shifts posterosuperiorly, which may give an aged appearance in the central superior sulcus (Fig. 1) [2]. 
In the lower eyelid, protrusion of nasal, central, and temporal fat pads occur. Atrophy and regression of soft tissues occur in the medial canthus region and in the soft tissues inferior to lower eyelid [3]. This forms a nasojugal groove, and the inferior orbital rim becomes visible (Fig. 2).

The lateral canthus shifts medially, which causes shortening of the horizontal palpebral fissure. This shortening may be attributable to progressive laxity of the lateral and medial canthal tendons (LCT and MCT) on aging [4]. The LCT is much weaker than the MCT, which leads to higher involvement of the LCT than of the MCT in most cases of eyelid laxity. Additionally, lower eyelid laxity also causes descent of the lateral canthus and inferior migration of the lower eyelid.

\section{Upper eyelid}

\section{Blepharoptosis}

Involutional blepharoptosis (ptosis) is classified as acquired

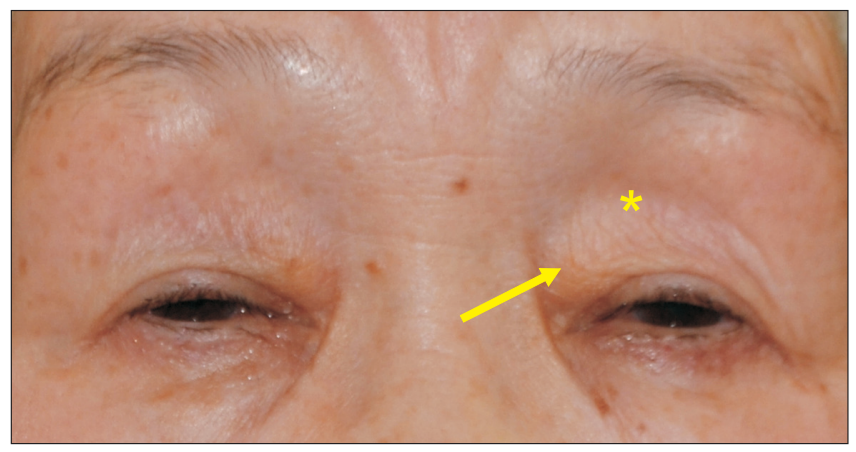

Fig. 1. Topographic change of the aging upper eyelid. This shows herniation of the nasal fat pad (arrow) and hollowing of the central superior sulcus (asterisk).

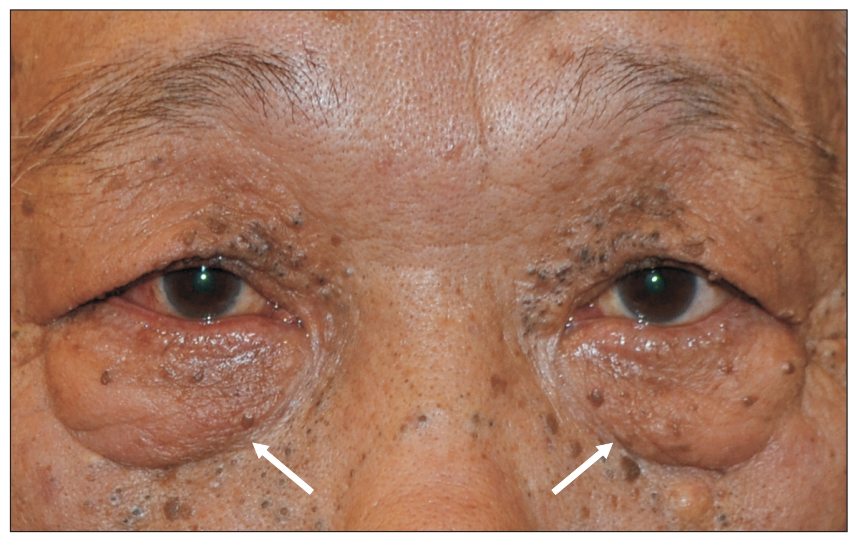

Fig. 2. Topographic change of the aging lower eyelid. This shows protrusion of the nasal, central, and temporal fat pads. The nasojugal groove is visible (arrow). aponeurotic ptosis. The upper eyelid margin is in the lower position on primary gaze (Fig. 3A). It causes a tired or sleepy appearance. In more severe cases, it causes superior visual field loss that is often worse on upgaze [5]. Patients tend to lift the eyelid by brow elevation, leading to deep forehead furrows and experiencing frontalis muscle fatigue and headache.

Aging and gravity contribute to its development. It is primarily caused by dehiscence, disinsertion, or stretching of the levator aponeurosis from the tarsus, and dehiscence of the medial limb of the Whitnall ligament. Fat infiltration in the levator aponeurosis, levator muscle, or Müller muscle often occur [6]. The Müller muscle becomes thinner with less collagen fibers and often exhibits fibrosis [6].

Recent studies revealed that aging changes in the levator muscle and aponeurosis are associated with oxidative stress, microischemia of collagen bundles, edema, mechanical stretching, and changes in hormone and cytokine levels associated with production and destruction of collagen fibers [7].

Generally, patients with involutional ptosis have normal $(>11 \mathrm{~mm})$ to slightly reduced levator function [8]. In this setting, the levator muscle has a normal function with disinserted or stretched levator aponeurosis. This usually requires levator aponeurosis advancement (Figs. 3B, 4). In this technique, the levator aponeurosis is detached from the tarsus, followed by separation from the Müller muscle and post-septal fat pad [9]. The levator aponeurosis is then advanced and fixed with one to
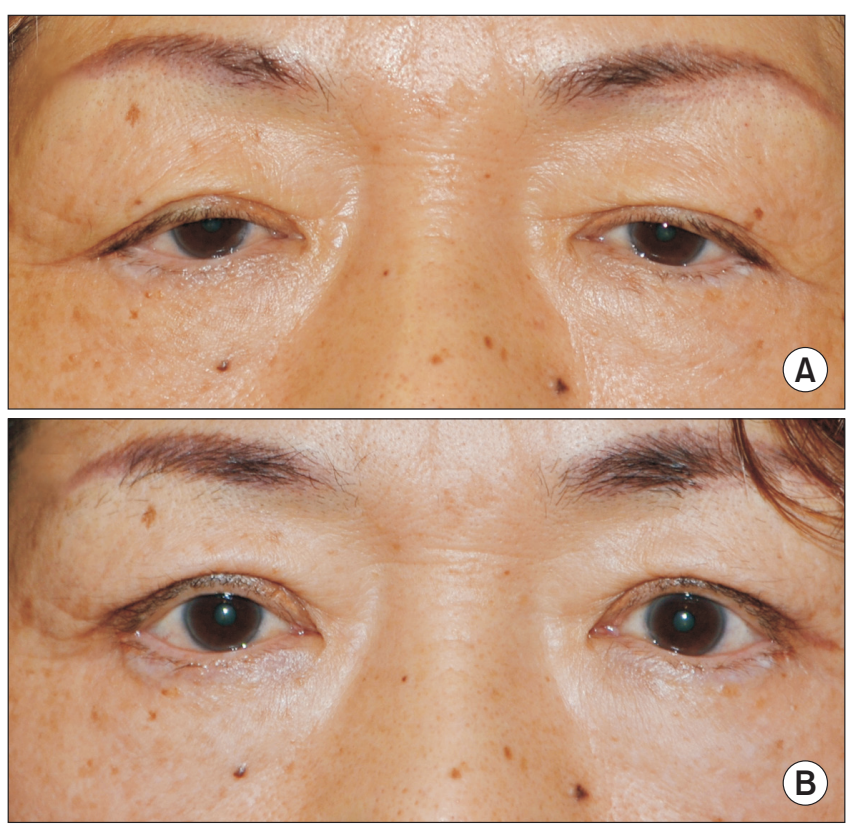

Fig. 3. Blepharoptosis. (A) Patient with blepharoptosis. (B) Outcome of levator advancement surgery. 


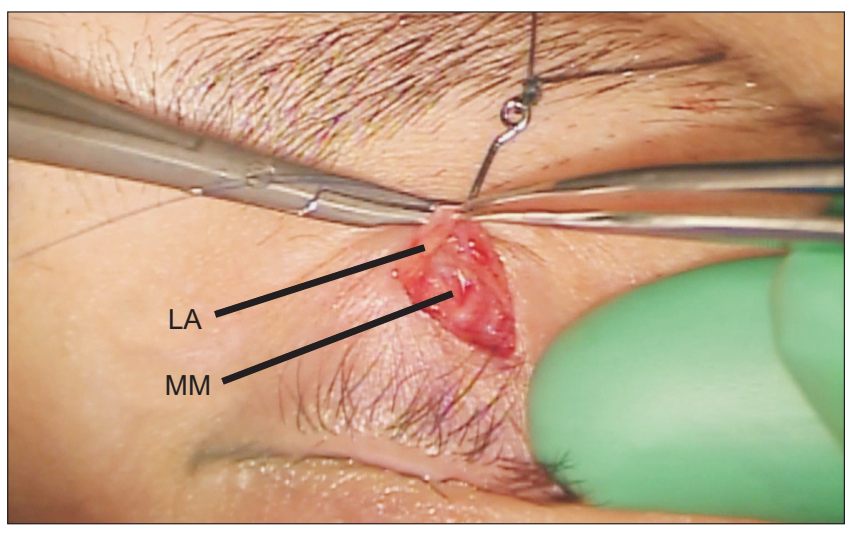

Fig. 4. Levator advancement surgery: detached levator aponeurosis (LA) from the Müller muscle (MM).
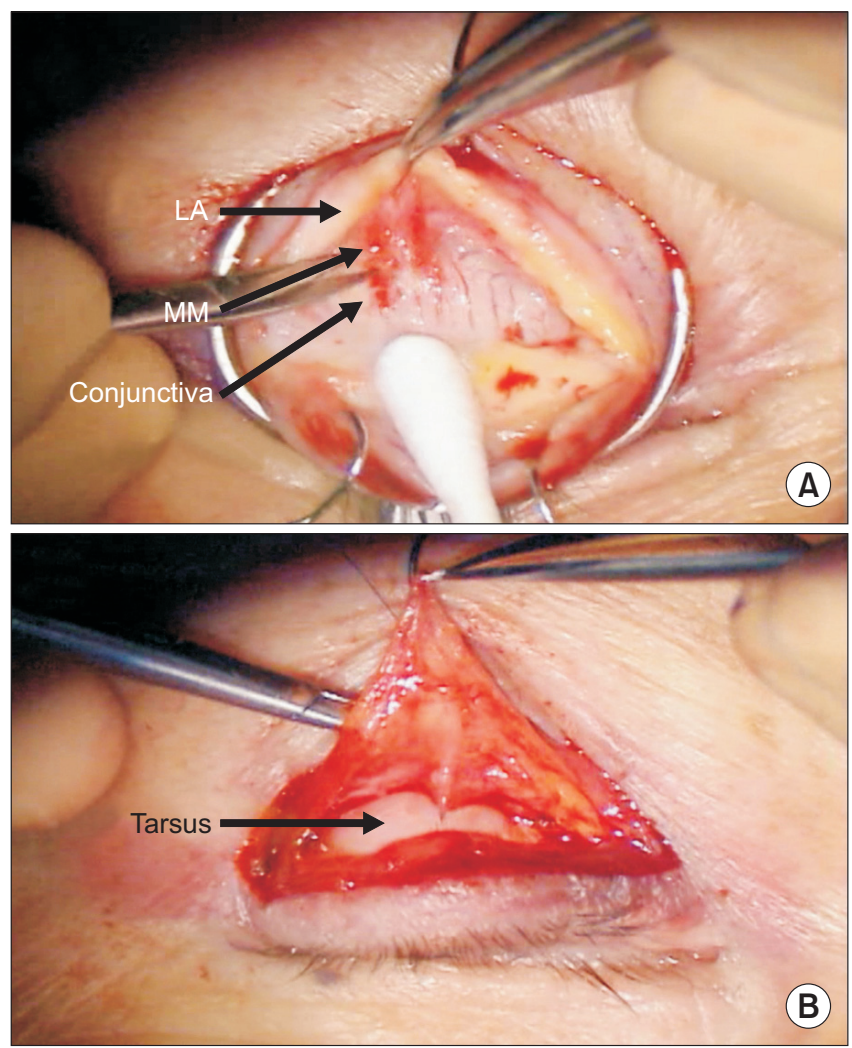

Fig. 5. Levator resection surgery. (A) Detachment of levator aponeurosis (LA) and Müller muscle (MM) complex from the conjunctiva. (B) Fixation of levator aponeurosis and Müller muscle complex to the tarsus.

three sutures to the tarsus.

In more severe ptosis, levator resection is performed (Fig. 5) [8]. The levator aponeurosis and the Müller muscle are not separated and are detached together from the conjunctiva and post-septal fat pad. Subsequently, the levator aponeurosis and Müller muscle are simultaneously advanced to the tarsus [10].

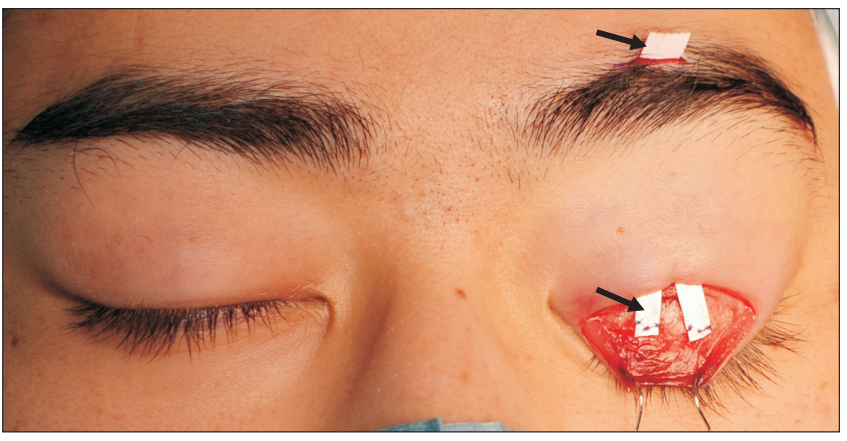

Fig. 6. Frontalis suspension surgery using Gore-Tex (arrow) on the left eyelid.

In poor $(<4 \mathrm{~mm})$ levator function, frontalis suspension surgery is needed (Fig. 6). The eyelid is suspended directly from the frontalis muscle with the use of autogenous or allograft fascia lata or other synthetic materials, such as Gore-Tex and silicon [8].

\section{Dermatochalasis}

Dermatochalasis is characterized by grossly redundant and lax skin (Figs. 7A, 8A) [11]. Similar to ptosis, patients with dermatochalasis are noticed to have tired or sleepy appearing eyes. They also experience gradual increasing heaviness of the eyelids [11]. Some patients also notice superior visual field obstruction due to sagging skin, which leads to compensatory frontalis contraction. In other cases, the redundant skin hangs over the lashes, often resulting in lash ptosis, leading to ocular irritation. In addition to sagging skin, bulging fat pad occur, which is often restricted to the nasal fat pad of upper lid.

With aging and gravity, parallel loss of elastic skin fibers, connective tissue weakening, epidermis thinning, and skin redundancy occur [1,12]. Microscopically, it shows markedly decreasing density of elastic fibers [12]. Lymphatic hyperplasia, dilated lymphatic vasculature, increased stromal edema, and collagen bundle dispersion are also evident, suggesting lymphedema [12]. In addition, macrophages are present, which, release degradative enzymes when activated, including elastase and collagenase that causes degradation of the structural component of the lymphatic vessels. This leads to lymphostasis and subsequent lymphedema [12]. Hence, the pathogenesis of dermatochalasis begins with subclinical inflammation and leads to skin edema and eventually skin redundancy.

Pinch blepharoplasty is the surgical procedure to correct dermatochalasis (Figs. 7B, C). The redundant skin is excised. The nasal fat pad often requires debulking if prominent. The central fat pads are generally left preserved. In East Asians, who have 

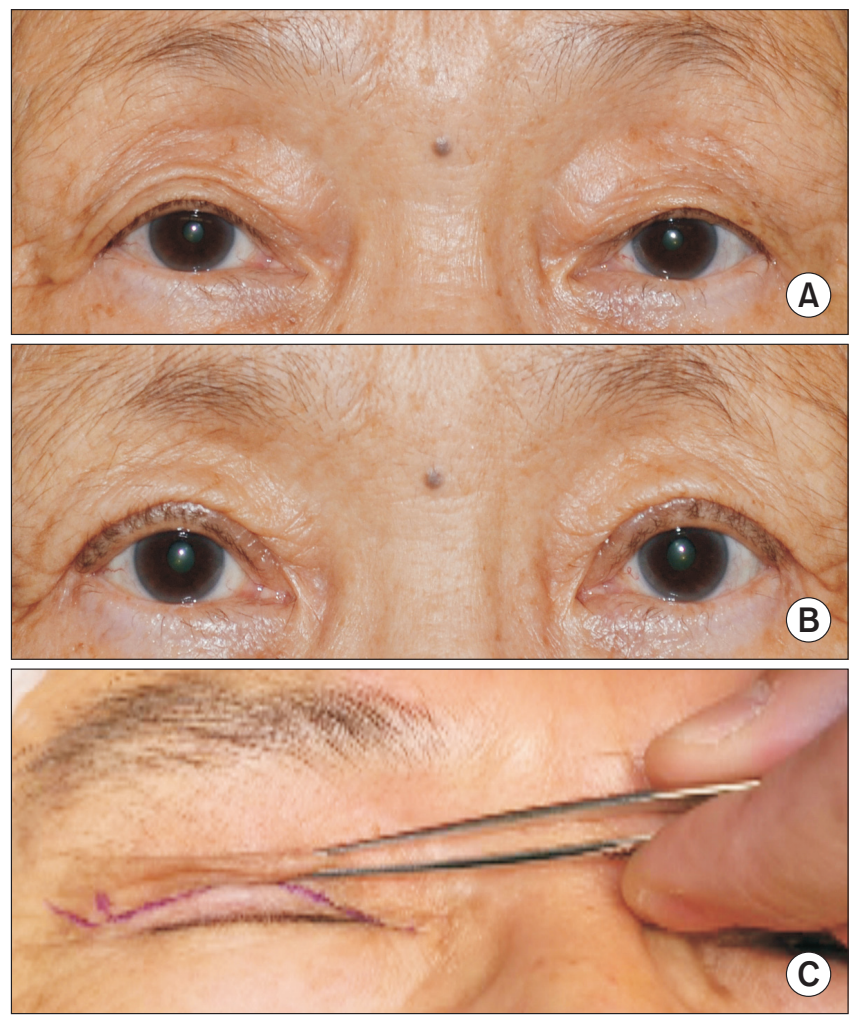

Fig. 7. Pinch blepharoplasty. (A) Pre-operative photograph of patient with dermatochalasis. (B) Outcome after pinch blepharoplasty. (C) Pinching of the upper eyelid during marking.

variable degrees of eyelid crease presence and more prominent lateral hooding, sub-brow blepharoplasty is commonly performed (Fig. 8).

\section{Increasing proportion of double eyelids with increasing age}

The frequency of double eyelid fold increases with age [13]. The distance between the eyelid skin fold and upper eyelid margin also increases with age [14]. This is associated with agerelated disinsertion of the levator muscle aponeurosis and involutional atrophy of orbital fat [14]. It may also be associated with upward shift of the eyebrows that occurs secondary to compensated increased frontalis action in patients who persistently lift their eyebrows in cases with dermatochalasis and ptosis [14]. In upper eyelid blepharoplasty, we should not only assess the amount of the excess skin and fat prolapse, but also assess and consider the position of the eyebrow, eyelid margin, eyelid crease, and eyelid folds.
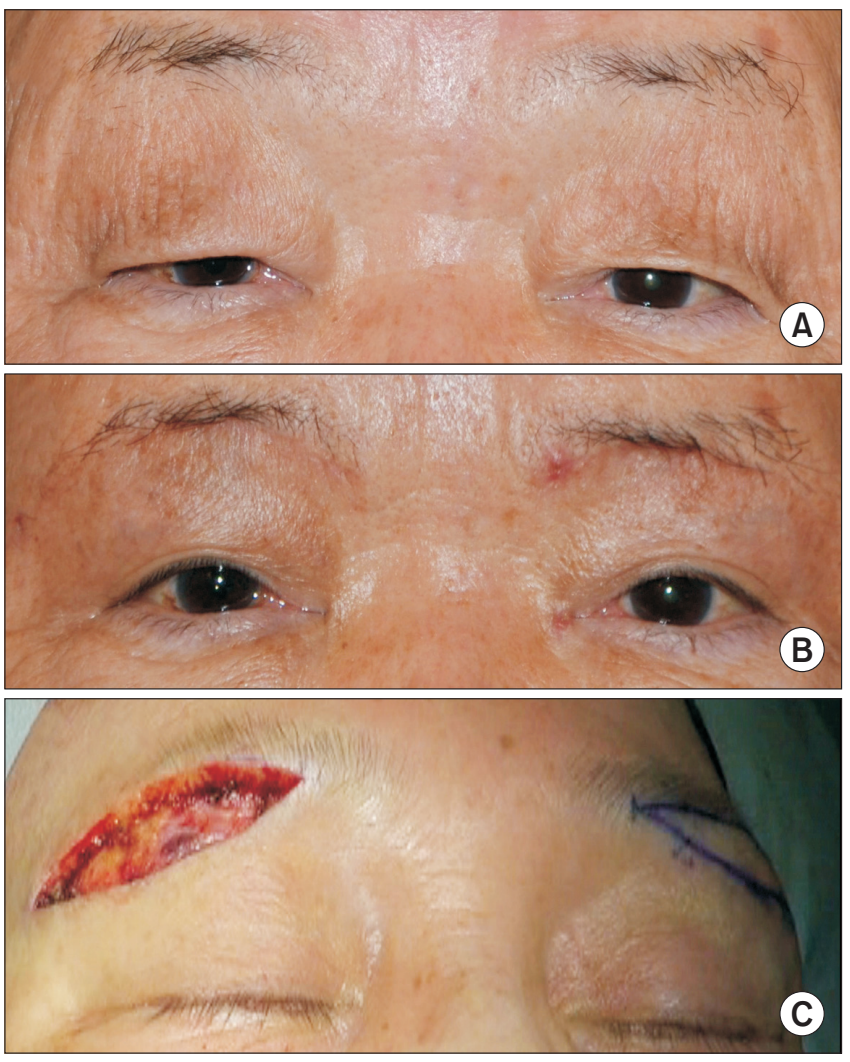

Fig. 8. Sub-brow blepharoplasty. (A) Pre-operative photograph of patient with dermatochalasis. (B) Outcome after sub-brow blepharoplasty, (C) Intra-operative surgery.

\section{Lower eyelid}

\section{Entropion}

Involutional entropion is an age-related eyelid malposition wherein the eyelid margin is inverted against the globe (Fig. 9A). This condition causes ocular surface irritation and other serious corneal complications.

The underlying cause of involutional entropion is multifactorial. The main mechanisms acknowledged are vertical eyelid laxity, horizontal eyelid laxity, and overriding of preseptal orbicularis oculi muscle to the pretarsal orbicularis muscle. In addition, the partial atrophy of orbital fat that results in enophthalmos promotes development of entropion [15].

Vertical eyelid laxity is caused by attenuation, dehiscence, or disinsertion of lower eyelid retractors (LER). The LER is composed of the capsulopalpebral head, capsulopalpebral fascia (CPF), and smooth muscles fibers [16]. The LER has two layers: the anterior and posterior layers [17]. Posterior layer laxity is mainly involved in vertical eyelid laxity $[16,17]$.

Horizontal eyelid laxity is caused by stretching of the MCT, LCT, and/or atrophic changes of the tarsal plate [16]. It is com- 

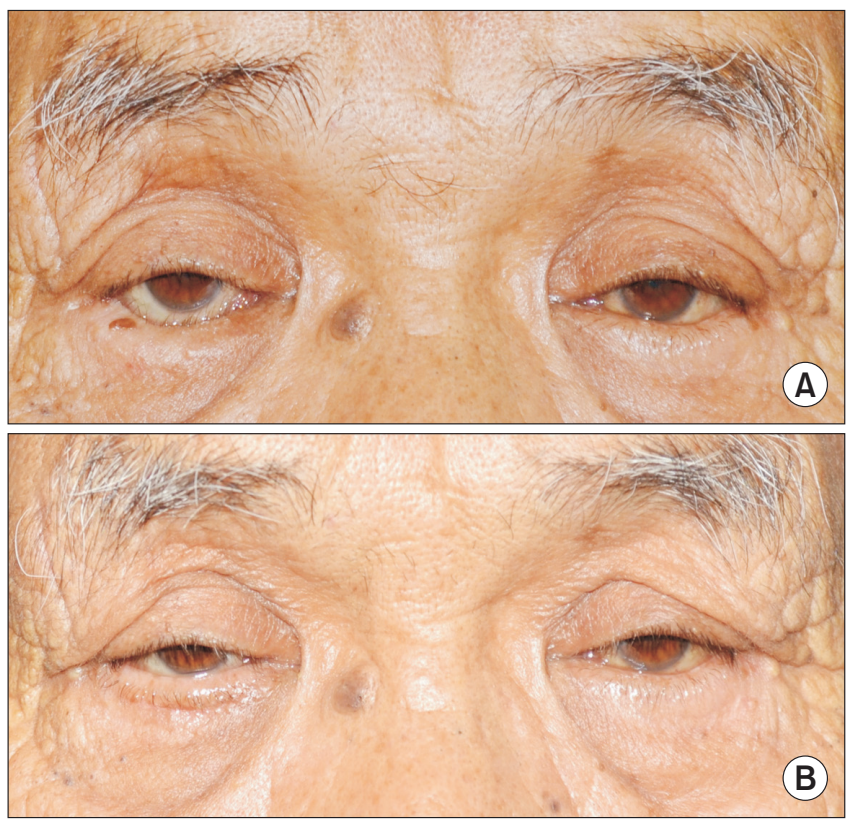

Fig. 9. Entropion. (A) Pre-operative photograph of a patient with right lower eyelid entropion. (B) Outcome after lower eyelid retractor advancement.

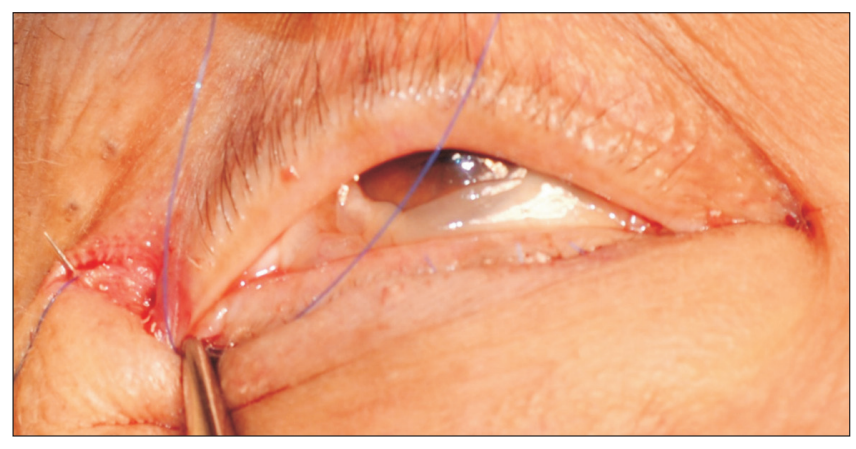

Fig. 10. Lateral canthopexy: suturing of lateral canthal tendon to the periosteum of the lateral orbital rim.

monly identified with positive pinch test (distraction test), which is able to pinch the central eyelid away from the globe $>8$ $\mathrm{mm}$ [17]. It can also be identified with positive snap back test, wherein the eyelid recoils slowly or after a blink after gently pulling the eyelid away from the globe and then releasing it.

The surgical approach is tailored to address the various anatomic factors contributing to entropion, which differs between patients. The attenuated LER may be strengthened by using Quickert sutures (everting sutures) or incisional approaches to advance the LER to the tarsus. The Quickert sutures also address the overriding preseptal orbicularis muscle. It involves placing horizontal mattress sutures through the full thickness of eyelid that results in eyelid eversion of variable duration [18]. It

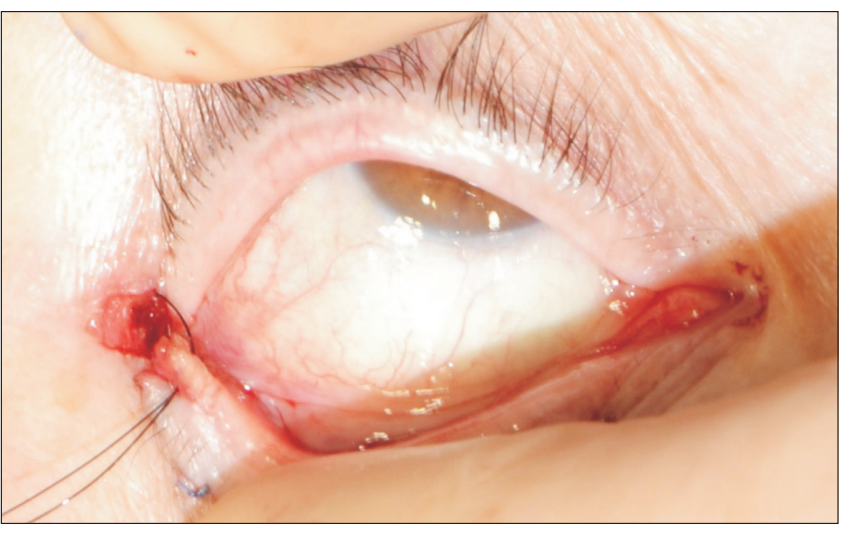

Fig. 11. Lateral tarsal strip procedure: suturing of the lateral tarsal strip.

is recommended for temporary repair and is useful for patients who are unable to tolerate more invasive surgeries. The modified Jones procedure (the lower eyelid retractors' advancement) is now commonly used to advance the LER (Fig. 9B) [19,20]. The anterior and posterior surfaces of the LER are detached. Subsequently, the posterior layer is advanced and fixed to the tarsus [20].

Several surgical procedures have been used to tighten the horizontal eyelid laxity. These include the transcanthal canthopexy [21], lateral tarsal strip (LTS) procedure [22], or horizontal eyelid-shortening procedures, such as Bick procedure [23]. Lateral canthopexy is used for less severe horizontal eyelid laxity (Fig. 10) [21,24]. After an incision is made in the lateral eyelid margin, a non-absorbable suture is passed to resuspend the lateral palpebral commissure to the periosteum of lateral orbital rim. For severe horizontal laxity, the lateral tarsal strip procedure is advised (Fig. 11) [24]. This procedure is started with lateral canthotomy and inferior cantholysis. Subsequently, the skin, orbicularis muscle, eyelash follicles, and conjunctiva around the lateral tarsal plate are excised. The stripped tarsal plate is sutured to the periosteum at the inner aspect of the lateral orbital rim [22]. For significant horizontal laxity with mild LCT laxity, the Bick procedure is performed (Fig. 12), which includes full-thickness pentagonal wedge removal of the lateral part of the eyelid, starting from the eyelid margin up to the level of the lower tarsal border [23].

\section{Ectropion}

Involutional ectropion is an age-related eyelid malposition, wherein the eyelid margin everts or is positioned away from its normal apposition to the globe (Fig. 13). Ectropion ranges from only punctum eversion, a degree of scleral show, or frank 


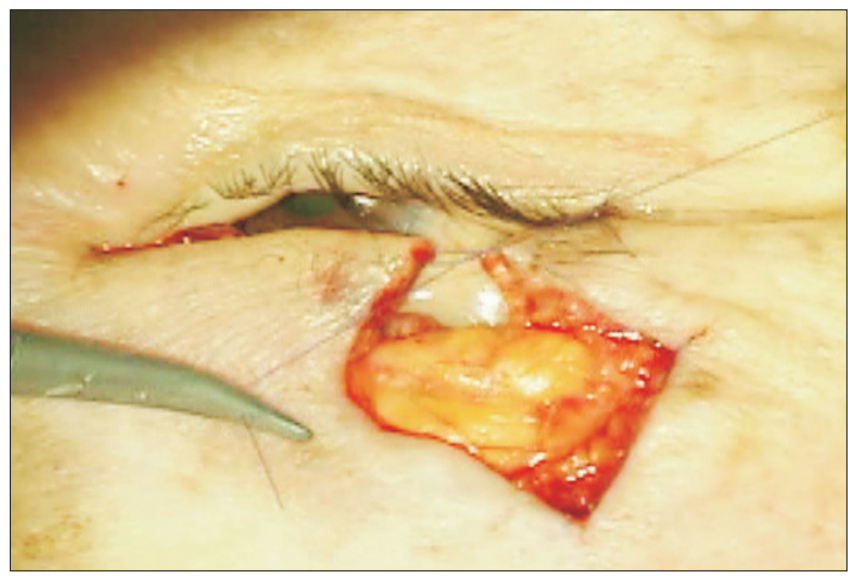

Fig. 12. Bick procedure.

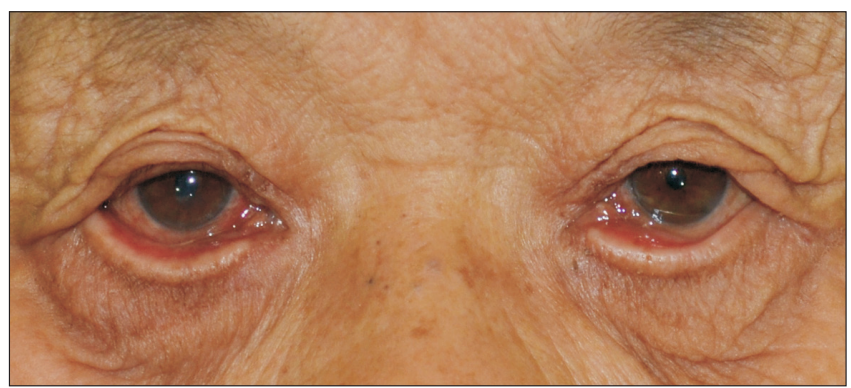

Fig. 13. Patient with bilateral ectropion.

rotation of the eyelid where the inner palpebral conjunctiva is exposed and visible. Punctum eversion is often the earliest condition that occurs, and it may cause epiphora with or without punctal occlusion [25]. Ectropion leads to palpebral conjunctival exposure, causing a secondary inflammation that results to conjunctival epithelium keratinization. Patients experience dry eye and may lead to exposure keratopathy.

Ectropion results from one or more anatomical defects in the eyelid. The choice of surgical procedure depends on the underlying defect and its severity. The main pathology is horizontal eyelid laxity from disinsertion or stretching of the MCT or LCT, or generalized tarsal redundancy. Horizontal eyelid laxity is first established using the pinch or snap back test. Subsequently, MCT laxity is determined by displacement of the inferior punctum position or positive lateral eyelid distraction test [26]. The inferior punctum is normally located just lateral to the caruncle at rest. Lateral distraction test is positive when the punctum is displaced more than half between the corneal limbus and the caruncle when the eyelid is pulled laterally [26]. In contrast, LCT laxity is present when the lateral canthus has a rounded appearance or has positive medial distraction test, where the lateral

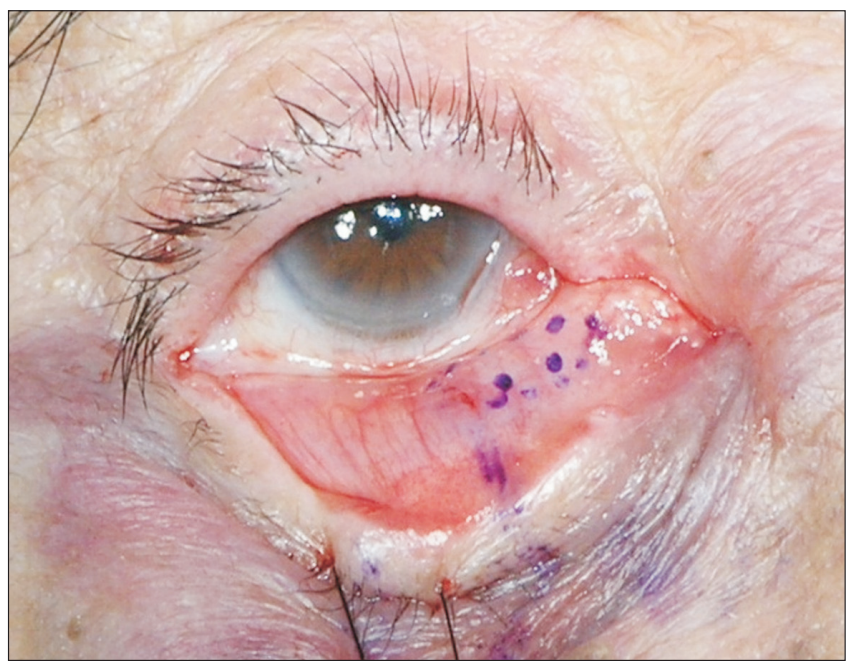

Fig. 14. Lazy-T procedure markings.

canthal angle moves $>2 \mathrm{~mm}$ when the lateral part of the eyelid is pulled medially.

Vertical eyelid laxity caused by laxity, dehiscence, or disinsertion of LER may also be associated with ectropion. In this case, the eyelid is completely everted with the tarsal plate turned upside down. Management requires advancement of the posterior layer of the LERs to the tarsal plate.

In ectropion involving only punctum eversion without significant horizontal eyelid laxity, a medial spindle excision is usually performed to vertically shorten the posterior lamella [27]. Medial spindle excision involves removal of a horizontal spindle shape conjunctiva and LER from inferior to the canaliculus followed by an inverting suture closure. In mild punctal ectropion, simple intubation can often correct the epiphora [25]. In punctal eversion with medial eyelid laxity, the "lazy-T procedure" is suggested (Fig. 14) [28]. The lazy-T procedure utilizes a full-thickness pentagon resection of the eyelid lateral to the punctum and does spindle excision of the conjunctiva and LER inferior to canaliculus [28].

In ectropion involving only mild MCT laxity, the lateral tarsal strip combined with medial spindle procedure is suggested. The lateral tarsal strip is preferred because MCT repair is complicated due to its intimate relation with the canaliculus. However, for moderate to marked MCT laxity, plication of the posterior limb of the MCT is advised [29]. This involves incision behind the caruncle and below the canaliculus, followed by tightening the medial canthus by suturing the periosteum of posterior lacrimal crest to the posterior limb of the MCT and medial edge of tarsus inferior to the canaliculus [29]. Resection of medial canthal structures with posterior fixation and canalicular repair is also 
suggested [30]. In this procedure, the medial canthal structures of the lower eyelid lateral to the caruncle are resected, and the posterior limb of the MCT is fixated with non-absorbable suture to the periosteum of posterior lacrimal crest. The inferior canaliculus is marsupialized into the lower conjunctival fornix [30].

In ectropion involving mild LCT laxity, a transcanthal canthopexy may be done. If it includes generalized horizontal eyelid laxity, the lateral tarsal strip is recommended [22]

In ectropion with significant horizontal eyelid laxity but mild MCT and LCT laxity, horizontal eyelid-shortening procedures, such as Bick [23] or Kuhnt-Szymanowski-Smith procedures are suggested [31,32]. The Kuhnt-Szymanowski-Smith procedure is performed when lower eyelid dermatochalasis accompanies ectropion. It involves undermining the skin flap from subcilial incision to the level of orbital rim. A pentagonal wedge resection of the lateral part of the posterior lamella of the lower eyelid follows. The redundant skin flap is pulled laterally, and the excess skin is trimmed appropriately $[31,32]$.

\section{Baggy eyelids}

Baggy eyelids show an appearance of lower eyelid fullness by bulging of the lower eyelid fat pads (Fig. 15). It is caused by downward and forward shift of the orbital fat, which bulges due to attenuation of the lower orbital septum and anchoring structures, such as the orbitomalar ligament, with aging [33]. Atrophy of the periorbital tissue along the orbital rim favors inferior descent of the orbital fats [33]. Descent of the globe from loosened orbital-supporting structures, such as the orbital septum, LER, and LCT also plays a role in baggy eyelids [34]. In patients with baggy eyelids, sunken upper eyelids also develop due to atrophy and displacement of the orbital fat [35]. In such patients, sunken eye disappears by pushing the lower eyelid. This indicates that the lower eyelid fat pad has continuity with the orbital tissue.

Lower eyelid blepharoplasty is performed to debulk the bulging fat pads (Fig. 15) [36]. Transcutaneous and transconjunc- tival approaches are used. Transcutaneous approach has an advantage to effectively address excess lower eyelid skin and orbicularis oculi muscle [36]. Ectropion and retraction are the main feared complications in the transcutaneous approach [36], which becomes less frequent with concomitant lateral canthal-supporting structures' suspension, such as canthopexy, canthoplasty, and other eyelid-shortening techniques [36]. Transconjunctival approach is popularized to prevent such complications [33]. However, tear trough deformity occasionally remains on both approaches [33]. Tear trough deformity can be addressed with orbital fat repositioning along the medial infraorbital rim and/or septal reset [37]. In the septal reset, the orbital septum and the herniated fat pads are redraped over the maxilla through a subperiosteal plane following the release of the arcus marginalis [37].

\section{Epicanthus}

Epicanthus is a vertical fold of skin over the angle of the inner canthus. The epicanthus has been suggested to represent arrest in development, excessive development of skin at the root of the nose, abnormally poor development of bones of the skull and nose, excess of orbicularis muscle and fibroadipose tissue underlying the fold, and abnormal tension forces of the skin by the orbicularis muscle [38].

Epicanthus is present in many infants and mostly disappears in a few years. In some East Asians, the epicanthus persists. It partially covers the upper eyelid eyelashes and results in appearance of short eyelashes. It also causes rounding of the medial canthal area, which gives an appearance of a short palpebral fissure. It can obscure the medial globe and inner punctum, which makes the pupils seem closer to the midline. Microscopically, it is composed of excessive skin, rich fibroadipose tissue, and malpositioned preseptal orbicularis muscle, which runs in an oblique direction that coincides with the direction of the epicanthus [39].

Various methods are being used to correct epicanthus, such
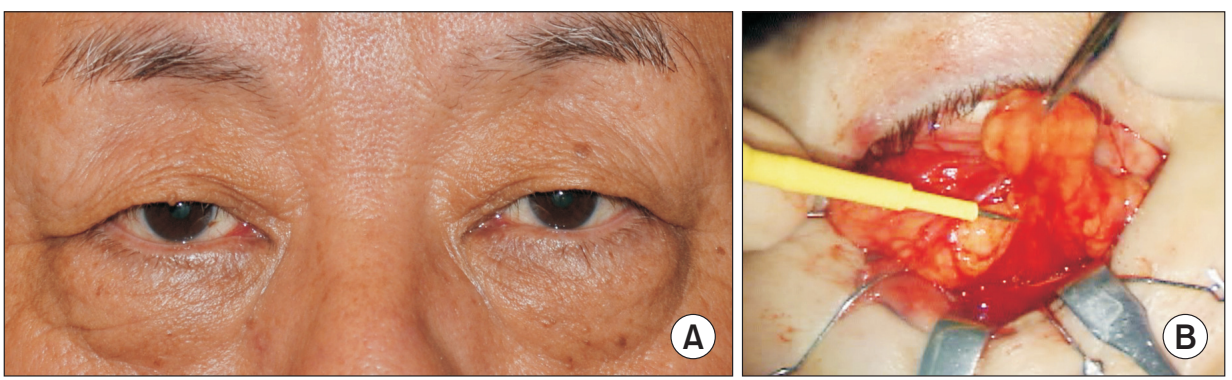

Fig. 15. (A) Patient with baggy eyelids. (B) Lower eyelid blepharoplasty. 
as skin excision, Z-plasty, and other advancement or transposition flap techniques, myotomy, or myectomy of the preseptal orbicularis muscle, and plication of the medial canthal ligament [38].

\section{Lateral canthal aging}

Medial and/or inferior shifts occur as age-related changes of the lateral canthus. Restoration of the position and tone is essential in lateral canthus correction [4]. A lateral canthal correction is commonly in conjunction with lower blepharoplasty to achieve optimal cosmetic outcome and prevention of surgical complication. As discussed earlier in this article, canthal surgery is also indicated for horizontal eyelid laxity-related entropion and ectropion. Canthal surgery involves lateral canthopexy [21], lateral canthoplasty [22], or tightening of the orbicularis oculi (orbicularis sling). In orbicularis sling, a rectangular strip of lateral orbicularis oculi muscle is sutured to the lateral orbital rim.

\section{Conflicts of interest}

The authors have nothing to disclose.

\section{References}

1. Pottier F, El-Shazly NZ, El-Shazly AE. Aging of orbicularis oculi: anatomophysiologic consideration in upper blepharoplasty. Arch Facial Plast Surg 2008;10:346-9.

2. Oh SR, Chokthaweesak W, Annunziata CC, Priel A, Korn BS, Kikkawa DO. Analysis of eyelid fat pad changes with aging. Ophthal Plast Reconstr Surg 2011;27:348-51.

3. Camp MC, Wong WW, Filip Z, Carter CS, Gupta SC. A quantitative analysis of periorbital aging with three-dimensional surface imaging. J Plast Reconstr Aesthet Surg 2011;64:148-54.

4. Lee H, Lee JS, Chang M, Park M, Baek S. Analysis of lid contour change with aging in Asians by measuring midpupil lid distance. Plast Reconstr Surg 2014;134:521e-9e.

5. Meyer DR, Linberg JV, Powell SR, Odom JV. Quantitating the superior visual field loss associated with ptosis. Arch Ophthalmol 1989;107:840-3.

6. Watanabe A, Araki B, Noso K, Kakizaki H, Kinoshita S. Histopathology of blepharoptosis induced by prolonged hard contact lens wear. Am J Ophthalmol 2006;141:1092-6.

7. Bailey AJ, Duance VC. Collagen in acquired connective tissue diseases: an active or passive role? Eur J Clin Invest 1980;10:13.
8. Edmonson BC, Wulc AE. Ptosis evaluation and management. Otolaryngol Clin North Am 2005;38:921-46.

9. Wada Y, Hashimoto T, Kakizaki H, Isogai N, Asamura S. What is the best way to handle the involutional blepharoptosis repair? J Craniofac Surg 2015;26:e377-80.

10. Noma K, Takahashi Y, Leibovitch I, Kakizaki H. Transcutaneous blepharoptosis surgery: simultaneous advancement of the levator aponeurosis and Müller's muscle (levator resection). Open Ophthalmol J 2010;4:71-5.

11. DeAngelis DD, Carter SR, Seiff SR. Dermatochalasis. Int Ophthalmol Clin 2002;42:89-101.

12. Nagi KS, Carlson JA, Wladis EJ. Histologic assessment of dermatochalasis: elastolysis and lymphostasis are fundamental and interrelated findings. Ophthalmology 2011;118:1205-10.

13. Onizuka T. Operative plastic and aesthetic surgery. 3rd ed. Tokyo: Nankodo; 1996.

14. van den Bosch WA, Leenders I, Mulder P. Topographic anatomy of the eyelids, and the effects of sex and age. Br J Ophthalmol 1999;83:347-52.

15. Collin JR, Rathbun JE. Involutional entropion. A review with evaluation of a procedure. Arch Ophthalmol 1978;96:1058-64.

16. Kakizaki H, Malhotra R, Madge SN, Selva D. Lower eyelid anatomy: an update. Ann Plast Surg 2009;63:344-51.

17. Kakizaki H, Zhao J, Nakano T, Asamoto K, Zako M, Iwaki M, et al. The lower eyelid retractor consists of definite double layers. Ophthalmology 2006;113:2346-50.

18. Quickert MH, Rathbun E. Suture repair of entropion. Arch Ophthalmol 1971;85:304-5.

19. Lee H, Takahashi Y, Ichinose A, Kakizaki H. Comparison of surgical outcomes between simple posterior layer advancement of lower eyelid retractors and combination with a lateral tarsal strip procedure for involutional entropion in a Japanese population. Br J Ophthalmol 2014;98:1579-82.

20. Kakizaki H, Zako M, Kinoshita S, Iwaki M. Posterior layer advancement of the lower eyelid retractor in involutional entropion repair. Ophthal Plast Reconstr Surg 2007;23:292-5.

21. Ishida Y, Takahashi Y, Kakizaki H. Posterior layer advancement of lower eyelid retractors with transcanthal canthopexy for involutional lower eyelid entropion. Eye (Lond) 2016;30:1469-74.

22. Anderson RL, Gordy DD. The tarsal strip procedure. Arch Ophthalmol 1979;97:2192-6.

23. Bick MW. Surgical management of orbital tarsal disparity. Arch Ophthalmol 1966;75:386-9.

24. Georgescu D. Surgical preferences for lateral canthoplasty and canthopexy. Curr Opin Ophthalmol 2014;25:449-54. 
25. Higaki F, Noma K, Takahashi Y, Kakizaki H. A case of medial ectropion cured after canaliculoplasty and intubation. Orbit 2013;32:60-2.

26. Olver JM, Sathia PJ, Wright M. Lower eyelid medial canthal tendon laxity grading: an interobserver study of normal subjects. Ophthalmology 2001;108:2321-5.

27. Nowinski TS, Anderson RL. The medial spindle procedure for involutional medial ectropion. Arch Ophthalmol 1985;103:1750-3.

28. Smith B. The "lazy-T" correction of ectropion of the lower punctum. Arch Ophthalmol 1976;94:1149-50.

29. Anderson RL, Hatt MU, Dixon R. Medial ectropion. A new technique. Arch Ophthalmol 1979;97:521-4.

30. Crawford GJ, Collin JR, Moriarty PA. The correction of paralytic medial ectropion. Br J Ophthalmol 1984;68:639-41.

31. Kuhnt H, Jena G, Fischer. Beitrage zur Operationen augenheikunder. Jena: G Fischer; 1883. p. 44-55.

32. Szymanowski J. Handbuch der Operationen Chirurgie. Berlin: Braunschweig; 1870. p. 243.
33. Richard MJ, Morris C, Deen BF, Gray L, Woodward JA. Analysis of the anatomic changes of the aging facial skeleton using computer-assisted tomography. Ophthal Plast Reconstr Surg 2009;25:382-6.

34. de la Plaza R, Arroyo JM. A new technique for the treatment of palpebral bags. Plast Reconstr Surg 1988;81:677-87.

35. Maniglia JJ, Maniglia RF, Jorge dos Santos MC, Robert F, Maniglia FF, Maniglia SF. Surgical treatment of the sunken upper eyelid. Arch Facial Plast Surg 2006;8:269-72.

36. Zoumalan CI, Roostaeian J. Simplifying blepharoplasty. Plast Reconstr Surg 2016;137:196e-213e.

37. Hamra ST. Arcus marginalis release and orbital fat preservation in midface rejuvenation. Plast Reconstr Surg 1995;96:35462.

38. Yoo WM, Park SH, Kwag DR. Root z-epicanthoplasty in asian eyelids. Plast Reconstr Surg 2002;109:2067-71; discussion 2072-3.

39. Kakizaki H, Ichinose A, Nakano T, Asamoto K, Ikeda H. Anatomy of epicanthal fold. Plast Reconstr Surg 2012;130: 494e-5e. 